\title{
Aid and the Public Sector in East Africa: Endogenous and Disaggregated Aid
}

\author{
Mohamed Abdel Rahman Salih \\ Department of Finance and Economics \\ College of Business Administration \\ Taibah University, P. O. Box 344, Medina, Saudi Arabia \\ E-mail:msalih@taibahu.edu.sa
}

Received: January 22, 2012

Accepted: March 15, 2012

Published: May 1, 2012

doi:10.5539/ijef.v4n5p186

URL: http://dx.doi.org/10.5539/ijef.v4n5p186

We acknowledge and appreciate comments by an anonymous referee. Any errors that remain are our responsibility.

\begin{abstract}
This paper addresses the question of the relationship between foreign aid and the fiscal behavior of the public sector in developing countries. We treat aid as an endogenous variable in the public sector's utility maximization problem. We also disaggregate the aid variable into three components of official development assistance. Data on the East African countries Ethiopia, Sudan, Kenya, Tanzania, and Uganda for the period 1990-2009 is used to estimate the parameters of the model. The results indicate that aid increases both public investment and recurrent government expenditure. The results also show that aid reduces taxation and domestic borrowing. An incremental aid results in much higher reduction in domestic borrowing than the reduction in Taxation.
\end{abstract}

Keywords: Disaggregated aid, Endogenous aid, Fiscal Response Models

\section{Introduction}

Since the late 1960s many underdeveloped countries have adopted economic planning to achieve rapid development with the public sector playing an important role in the planning and implementation of development projects. These countries have received substantial amounts of foreign aid in different forms. Yet, no significant improvements in the economic growth rates were observed in many of these countries. This led economists to question the effectiveness of foreign aid in promoting growth and development. Since the publication of the influential paper by Heller (1975) on the fiscal behavior of the public sector in the presence of aid, large amounts of work have been done on aid effectiveness and the fiscal response. Nevertheless, the results of the aid effectiveness and the fiscal response have not been quite conclusive. Heller (1975) using a cross-section study of some African countries shows that aid increases the public expenditure on investment and reduces the public sector's current expenditure. His results also confirm the Please's hypothesis. Khan \& Hoshino (1992) show, in a cross-section study of Asian countries, that aid increases public investment, current government spending, and as well the tax revenue. Iqbal (1997) using a time series study of Pakistan shows that aid increases government current expenditure. Franco-Rodriguez et al (1998) using a time series study of Pakistan show that the total of effect of aid on public investment is positive, the total effect of aid government current spending is negative, and the total effect of aid on taxation is negative. Franco-Rodriguez (2000) in a time series study of Costa Rica shows that the total effect of aid on public investment and public borrowing is negative, while the total effect of aid on government current spending and taxation is positive. Phijaisant (2010) using a time series study of Thailand shows that aid increases current government expenditure and reduces tax revenue.

The primary purpose of this paper is to empirically assess the relationship between three types of official development assistance (ODA) and the public sector's investment and consumption in the context of East Africa. The countries that are included in this study are: Ethiopia, Sudan, Kenya, Tanzania, and Uganda. The choice of the countries was dictated by the availability of data. This paper adapts the works of Franco-Rodriguez et al (1998), Mavrotas (2004), Mavrotas (2005), and Mavrotas \& Ouattara (2006). Franco-Rodriguez et al introduce in their paper the view of endogenous aid. Previous fiscal response literature treats aid as an exogenous variable since the recipient countries have no direct control over the amount of aid by donors. However, Franco-Rodriguez et al maintain that even though the recipient countries have no direct control over aid; they do have effective control over 
the amounts to be spent (disbursements) given commitments by donors. Commitments by donors are beyond the control of the recipient country and as such they cannot constrain the utility maximization problem of the public sector. With this justification, they treat the aid variable (disbursements) as a choice variable in the public sector's utility maximization problem. Mavrotas (2004), on the other hand, argues for disaggregation of the aid variable. He emphasizes on the importance of taking into account the heterogeneity of aid when modeling fiscal response models. He justifies his proposal on two grounds. Firstly, different types of aid operate in different ways in the recipient country thus resulting in different macro effects. Secondly, because of different conditions relating to each in different countries, there is also an extra reason to expect different effect of aid in each country. From these he concludes that failing to account for the heterogeneity of aid will disturb the empirical results. Mavrotas and Ouattara (2006) treat the disaggregated aid components (i.e. project aid, program aid, technical assistance and food aid) as endogenous variables. In this paper we disaggregate the aid variable into three ODA components (loans, grants, and technical assistance) and treat them as choice variables in the utility maximization problem of the public sector.

The plan of the paper is as follows. Section 2 develops the theoretical framework. Section 3 describes the data used and the estimation technique employed. Section 4 presents the results of the models. Section 5 wraps it up with some concluding remarks.

\section{The Theoretical Framework}

As in the standard response literature, we assume that the public sector aims to maximize the public utility by appropriately allocating the revenue generated from domestic borrowing, taxes, and foreign aid, among public investment and current public consumption expenditure. The following general form of utility function is used in this paper,

$$
\mathrm{U}=\mathrm{U}\left(I_{g}, G, A_{1}, A_{2}, A_{3}, T, B\right)
$$

where,

$\mathrm{U}=$ utility function of the public sector,

$I_{g}=$ public investment expenditure for development purposes,

$G=$ government current consumption expenditure,

$A_{1}=$ ODA loans disbursements from all foreign sources,

$A_{2}=$ ODA grants disbursements from all foreign sources,

$A_{3}=$ technical assistance disbursements from all foreign sources.

$T=$ total tax revenue collected by the public sector, and

$B$ = public borrowing from domestic sources.

The public sector's policymakers are assumed to behave rationally and maximize utility. In the fiscal response literature, it is assumed that governments set targets for the various expenditures as well as for the revenue variables taxation and domestic borrowing. Following Mosley et al (1987) and Binh and McGillivray (1993), the utility function in (1) can be expressed as a quadratic loss function as follows:

$$
\begin{gathered}
\mathrm{U}=\alpha_{0}-\left(\alpha_{1} / 2\right)\left(I_{g}-I_{g}^{*}\right)^{2}-\left(\alpha_{2} / 2\right)\left(G-G^{*}\right)^{2}-\left(\alpha_{3} / 2\right)\left(A_{1}-A_{1}^{*}\right)^{2}-\left(\alpha_{4} / 2\right)\left(A_{2}-A_{2}^{*}\right)^{2}-\left(\alpha_{5} / 2\right)\left(A_{3}-A_{3}^{*}\right)^{2}- \\
\left(\alpha_{6} / 2\right)\left(T-T^{*}\right)^{2}-\left(\alpha_{7} / 2\right)\left(B-B^{*}\right)^{2}
\end{gathered}
$$

where $\alpha_{i} \geq 0$ for $\mathrm{i}=1,2,3,4,5,6$, and 7 , and the starred variables indicate the target level for the given variable. Unfortunately, the target level variables are not available and thus they have to be somehow estimated. Two approaches are available in the empirical literature. The first approach is to regress each choice variable on the exogenous variables that are assumed to determine the target level of the choice variable. Then use the predicted values of the choice variable as the target level variable. The second approach is to specify a target variable as a function of exogenous variables that are assumed to affect the target variable and then plug it in the structural equations. Both approaches have been criticized for good reasons, but the critics do not offer a better treatment of the target variables - see e.g. McGillivray and Morrissey (2001). The target aid variables are commitments by donors for a given year. Commitments are made by donors and it is left for the recipient country to decide how much of commitments to use. It makes perfect sense to view commitments as the target level of disbursements. This is a practice that is used by many authors in recent years - see for example Franco-Rodriguez (1998) and Mavrotas (2004). This treatment also makes sense intuitively since the donors determine the amount of aid committed and it is up to the recipient country to determine the amount to be disbursed given the commitments. The target variable for the development expenditure $I_{g}^{*}$ is assumed to depend on the levels of private investment and the previous year's 
income. This specification was first used by Heller (1975) per Harrod-Domar model. The target level of the public current consumption $G^{*}$ is assumed to depend on primary school enrollment, the income level, and the previous year's public expenditure. The target level of the tax revenue $T^{*}$ is assumed to depend on the previous year's income and imports. These specifications are also used by previous studies - see e.g. Heller (1975). As is the case with previous studies also, the desired level of public borrowing from domestic sources, $B^{*}$ is set to zero. The justification being public borrowing from domestic sources is regarded as the last resort to finance the expenditures of the public sector.

Following Franco-Rodriguez et al, we assume that the policy makers of the public sector maximize the above utility function subject to the following constraints:

$$
\begin{gathered}
I_{g}+G=A_{1}+A_{2}+A_{2}+T+B \\
G \leq \rho_{1} A_{1}+\rho_{2} A_{2}+\rho_{3} A_{3}+\rho_{4} T+\rho_{5} B
\end{gathered}
$$

where, $0 \leq \rho_{i} \leq 1$ for $\mathrm{i}=1,2,3,4$ and 5. Franco-Rodriguez et al reject the constraints used in the standard fiscal response literature on three grounds. Firstly, it is implicitly assumed that donors grant aid for the purpose of investment only (and that all investment expenditures are captured in $I_{g}$ ), hence any aid allocated to $G$ is an ex post

measure of fungibility. Secondly, the standard fiscal response literature constraints do not allow for the common practice in developing countries of financing current expenditure from domestic borrowing. Thirdly, and as pointed out by White (1994), the representation of the standard fiscal response constraints over-constraints the model, not necessarily allowing the government to reach $\alpha_{0}$ even in the case where aid revenue is sufficient to meet all targets. This problem arises because although revenue may be sufficient to meet all the expenditures, the $\rho$ s constrain allocation so that specific expenditure targets in (2) cannot be met. In the formulation (3) and (4), the parameters $\rho_{1}, \rho_{1}, \rho_{3}, \rho_{4}$, and $\rho_{5}$ are of special interest as they reflect the way in which the public sector uses its resources to finance different components of its expenditure.

We now maximize the utility function specified in (2) with respect to the endogenous variables $I_{g}, G, A_{1}, A_{2}, A_{3}, T$, and $B$, subject to the fiscal constraints specified in (3) and (4).

$$
\begin{array}{r}
\operatorname{Max} \ell=\alpha_{0^{-}}\left(\alpha_{1} / 2\right)\left(I_{g}-I_{g}^{*}\right)^{2}-\left(\alpha_{2} / 2\right)\left(G-G^{*}\right)^{2}-\left(\alpha_{3} / 2\right)\left(A_{1}-A_{1}^{*}\right)^{2}-\left(\alpha_{4} / 2\right)\left(A_{2}-A_{2}^{*}\right)^{2}-\left(\alpha_{5} / 2\right)\left(A_{3}-A_{3}^{*}\right)^{2}- \\
\left(\alpha_{6} / 2\right)\left(T-T^{*}\right)^{2}-\left(\alpha_{7} / 2\right)\left(B-B^{*}\right)^{2}+\lambda_{1}\left[I_{g}+G-A_{1}-A_{2}-A_{3}-T-B\right]+\lambda_{2}\left[G-\rho_{1} A_{1}-\rho_{2} A_{2}-\rho_{3} A_{3}-\rho_{4} T-\right. \\
\left.\rho_{5} B\right]
\end{array}
$$

where $\lambda_{1}$ and $\lambda_{2}$ are the Lagrangian multipliers. The first-order conditions (FOCs) of the maximization of $\ell$ are as follows:

$$
\begin{gathered}
\partial \ell / \partial I_{g}=-\alpha_{1}\left(I_{g}-I_{g}^{*}\right)+\lambda_{1}=0 \\
\partial \ell / \partial G=-\alpha_{2}\left(G-G^{*}\right)+\lambda_{1}+\lambda_{2}=0 \\
\partial \ell / \partial A_{1}=-\alpha_{3}\left(A_{1}-A_{1}^{*}\right)-\lambda_{1}-\lambda_{2} \rho_{1}=0 \\
\partial \ell / \partial A_{2}=-\alpha_{4}\left(A_{2}-A_{2}^{*}\right)-\lambda_{1}-\lambda_{2} \rho_{2}=0 \\
\partial \ell / \partial A_{3}=-\alpha_{5}\left(A_{3}-A_{3}^{*}\right)-\lambda_{1}-\lambda_{2} \rho_{3}=0 \\
\partial \ell / \partial T=-\alpha_{6}\left(T-T^{*}\right)-\lambda_{1}-\lambda_{2} \rho_{4}=0 \\
\partial \ell / \partial B=-\alpha_{7}\left(B-B^{*}\right)-\lambda_{1}-\lambda_{2} \rho_{5}=0 \\
\partial \ell / \partial \lambda_{1}=I_{g}+G-A_{1}-A_{2}-A_{3}-T-B=0 \\
\partial \ell / \partial \lambda_{2}=G-\rho_{1} A_{1}-\rho_{2} A_{2}-\rho_{3} A_{3}-\rho_{4} T-\rho_{5} B=0
\end{gathered}
$$

Upon rearranging the FOCs, substituting out $\lambda_{1}$ and $\lambda_{2}$, and imposing $B^{*}=0$ we obtain the following structural equations:

$$
\begin{aligned}
& I_{g}=\left(1-\rho_{4}\right) \beta_{4} I_{g}^{*}+\left(1-\rho_{4}\right)\left(\beta_{4}+\beta_{9}\right) G^{*}+\left(1-\rho_{4}\right)\left[1-\rho_{4} \beta_{9}-\beta_{4}\right] T^{*}+\sum_{i=1}^{3}\left[\left(1-\rho_{i}\right)-\left(1-\rho_{4}\right)\left(\rho_{i} \beta_{9}+\beta_{4}\right)\right] A_{i}+ \\
& {\left[\left(1-\rho_{5}\right)-\left(1-\rho_{4}\right)\left(\rho_{5} \beta_{9}+\beta_{4}\right)\right] B} \\
& G=\rho_{4} \beta_{4} I_{g}^{*}+\rho_{4}\left(\beta_{4}+\beta_{9}\right) G^{*}+\rho_{4}\left[1-\rho_{4} \beta_{9}-\beta_{4}\right] T^{*}+\sum_{i=1}^{3}\left[\rho_{i}-\rho_{4}\left(\rho_{i} \beta_{9}+\beta_{4}\right)\right] A_{i}+\left[\rho_{5}-\rho_{4}\left(\rho_{5} \beta_{9}+\beta_{4}\right)\right] B(16) \\
& T=\beta_{4} I_{g}^{*}+\left[1-\rho_{4} \beta_{9}-\beta_{4}\right] T^{*}+\left(\beta_{4}+\beta_{9}\right) G^{*}-\sum_{i=1}^{3}\left(\rho_{i} \beta_{9}+\beta_{4}\right) A_{i}-\left(\rho_{5} \beta_{9}+\beta_{4}\right) B \\
& A_{1}=\beta_{1} I_{g}^{*}+\left(\beta_{1}+\beta_{6}\right) G^{*}-\left[1-\rho_{1} \beta_{6}-\beta_{1}\right] A_{1}^{*}-\sum_{i=2}^{3}\left(\rho_{i} \beta_{6}+\beta_{1}\right) A_{i}-\left(\rho_{4} \beta_{6}+\beta_{1}\right) T-\left(\rho_{5} \beta_{6}+\beta_{1}\right) B \\
& A_{2}=\beta_{2} I_{g}^{*}+\left(\beta_{2}+\beta_{7}\right) G^{*}-\left[1-\rho_{2} \beta_{7}-\beta_{2}\right] A_{2}^{*}-\sum_{i=1,3}\left(\rho_{i} \beta_{7}+\beta_{2}\right) A_{i}-\left(\rho_{4} \beta_{7}+\beta_{2}\right) T-\left(\rho_{5} \beta_{7}+\beta_{2}\right) B \\
& A_{3}=\beta_{3} I_{g}^{*}+\left(\beta_{3}+\beta_{8}\right) G^{*}-\left[1-\rho_{3} \beta_{8}-\beta_{3}\right] A_{3}^{*}-\sum_{i=1}^{2}\left(\rho_{i} \beta_{8}+\beta_{3}\right) A_{i}-\left(\rho_{4} \beta_{8}+\beta_{3}\right) T-\left(\rho_{5} \beta_{8}+\beta_{3}\right) B
\end{aligned}
$$




$$
B=\beta_{5} I_{g}^{*}+\left(\beta_{5}+\beta_{10}\right) G^{*}-\sum_{i=1}^{3}\left(\rho_{i} \beta_{10}+\beta_{5}\right) A_{i}-\left(\rho_{4} \beta_{10}+\beta_{5}\right) T
$$

where, for $\mathrm{i}=1,2,3,4$, and 5 :

$$
\begin{gathered}
\beta_{i}=\alpha_{1}\left(1-\rho_{i}\right) /\left[\alpha_{i+2}+\alpha_{2} \rho_{i}{ }^{2}+\alpha_{1}\left(1-\rho_{i}\right)^{2}\right], \\
\beta_{i+5}=\left[\alpha_{2} \rho_{i}-\alpha_{1}\left(1-\rho_{i}\right) /\left[\alpha_{i+2}+\alpha_{2} \rho_{i}{ }^{2}+\alpha_{1}\left(1-\rho_{i}\right)^{2}\right]\right.
\end{gathered}
$$

The reduced-form equations (22)-(28) can be obtained by solving for the endogenous variables in the above system of structural equations. The estimated parameters show the effect of the target level variables on each of the revenue and expenditure variables. The formulas of the parameters of the reduced-form equations are provided in the Appendix.

$$
\begin{aligned}
I_{g}= & \pi_{11} I_{g}^{*}+\pi_{12} G^{*}+\pi_{13} T^{*}+\pi_{14} A_{1}^{*}+\pi_{15} A_{2}^{*}+\pi_{16} A_{3}^{*} \\
G= & \pi_{21} I_{g}^{*}+\pi_{22} G^{*}+\pi_{23} T^{*}+\pi_{24} A_{1}^{*}+\pi_{25} A_{2}^{*}+\pi_{26} A_{3}^{*} \\
& A_{1}=\pi_{31} I_{g}^{*}+\pi_{32} G^{*}+\pi_{33} T^{*}+\pi_{34} A_{1}^{*}+\pi_{35} A_{2}^{*}+\pi_{36} A_{3}^{*} \\
& A_{2}=\pi_{41} I_{g}^{*}+\pi_{42} G^{*}+\pi_{43} T^{*}+\pi_{44} A_{1}^{*}+\pi_{45} A_{2}^{*}+\pi_{46} A_{3}^{*} \\
& A_{3}=\pi_{51} I_{g}^{*}+\pi_{52} G^{*}+\pi_{53} T^{*}+\pi_{54} A_{1}^{*}+\pi_{55} A_{2}^{*}+\pi_{56} A_{3}^{*} \\
T= & \pi_{61} I_{g}^{*}+\pi_{62} G^{*}+\pi_{63} T^{*}+\pi_{64} A_{1}^{*}+\pi_{65} A_{2}^{*}+\pi_{66} A_{3}^{*} \\
B= & \pi_{71} I_{g}^{*}+\pi_{72} G^{*}+\pi_{73} T^{*}+\pi_{74} A_{1}^{*}+\pi_{75} A_{2}^{*}+\pi_{76} A_{3}^{*}
\end{aligned}
$$

\section{Data and Estimation}

Data on 5 East African countries is used to estimate the parameters of the structural equations specified in (15) - (21) and the parameters of the reduced-form equations (22) - (28). All the variables, except aid variables, are obtained from the World Bank's African Development Indicators (ADI). The aid variables are obtained from OCED statistics. All the variables are measured in current US dollars to unify the units of different measurements across countries and then deflated by the country specific GDP deflator. We use recent data from 1990 to 2009. The target aid variables are the commitments by donors. The remaining target variables are estimated using cointegrating regression. This approach is used by Gang and Khan (1991), Khan and Hoshino (1992), Otim (1996), and Ahmed (2002). The parameters of the structural equations (15) - (21) are estimated using the nonlinear three-stage least squares (N3SLS) technique and the parameters of the reduced-form equations (22) - (28) are estimated using the ordinary least squares (OLS) technique.

\section{Empirical Results}

In this section we present the results of the estimation of the parameters of the structural equations and the reduced-form equations. We should keep in mind that, theoretically, it is expected that the recipient country devotes all three ODA components for development purposes. However, this is generally not the case in developing countries. The public sectors of these countries generally view aid as an extra revenue. The decision of how much of each aid component to devote to recurrent consumption expenditure will differ from one country to another. As a result, it is best to conduct this type of study using time series data for a specific country. However, lack of long time series data for most developing countries hinders country-specific studies. Having said this, we should emphasize that it is difficult to attach economic intuition to the heterogeneous effects of different components of aid on each expenditure type. The estimates of the parameters of the structural equations (15)-(21) are presented in Table 1 . The estimates of the constraint equation parameters $\rho_{1}, \rho_{2}, \rho_{3}, \rho_{4}$, and $\rho_{5}$ are statistically significant at the $5 \%$ level or lower except $\rho_{3}$, which is statistically insignificant. The estimates of these parameters suggest that $47 \%$ of ODA loans, $93 \%$ of ODA grants, $11 \%$ of technical assistance funds, $23 \%$ of taxes, and $73 \%$ of domestic borrowing are allocated to current public consumption expenditure. In other words, $53 \%$ of ODA loans, $7 \%$ of ODA grants, $89 \%$ of technical assistance funds, $77 \%$ of taxes, and $27 \%$ of domestic borrowing are allocated to the public investment expenditure. The estimate of $\rho_{5}$ confirms the assumption that the least developed governments do rely on domestic borrowing to finance recurrent expenditure. Most of the remaining structural parameters are significant at the $5 \%$ level.

Table 2 computes the direct effect of the revenue variables on expenditure and revenue variables. These are the coefficients associated with the endogenous variables on the right-hand side of the equations in (15)-(21). The results indicate that different aid variables do not necessarily have the same impact on revenue and expenditure variables. The direct effect of the three aid variables on public investment is positive and hence the combined effect of aid on public investment is positive. This confirms the results of Heller (1975), Khan \& Hoshino (1992), and Franco-Rodriguez et al (1998). The direct effects of ODA loans and ODA grants on current expenditure are positive while the direct effect of technical assistance on current spending is negative. The combined effect of aid on current 
expenditure is positive. This confirms the results of Khan \& Hoshino (1992), Iqbal (1997), McGillivray \& Ahmed (1999), and Franco-Rodriguez (2000). The incremental impact of loans and technical assistance on taxation is negative. On the other hand, taxation increases with increased ODA grants. The combined effect of aid on taxation is negative. This confirms the findings of Heller (1975) and Franco-Rodriguez et al (1998). The incremental impact of all three aid variables on domestic is borrowing is negative. For instance, the increase of ODA loans by $\$ 1$ reduces public borrowing by about $\$ 1.17$. This result supports the findings of Franco-Rodriguez et al (1998) and Franco-Rodriguez (2000). We make the following conclusions from Table 1 . The direct effect of a $\$ 1$ increase in aid disbursements increases the public investment expenditure by $\$ 0.27$. The direct effect of a $\$ 1$ increase in aid disbursements increases the current government expenditure by $\$ 0.98$. The direct effect of a $\$ 1$ increase in aid disbursements decreases taxation by $\$ 1.57$. Finally, the direct effect of a $\$ 1$ increase in aid disbursements decreases domestic borrowing by $\$ 3.62$.

Table 3 presents the estimates of the parameters of the reduced-form equation. Of particular interest, are the effects of aid commitments on revenue and expenditure variables. ODA loans commitments reduce the public investment $\left(\pi_{14}\right)$, while ODA grants and technical assistance commitments increase the public investment $\left(\pi_{15}\right.$ and $\left.\pi_{16}\right)$. The combined effect of aid commitments on public investment is positive. An increase in aid commitments by $\$ 1$ increases public investment by $\$ 0.63$. This result confirms the finding of Franco-Rodriguez et al (1998) in the context of Pakistan and in contrast of Franco-Rodriguez (2000) in the context of Costa Rica. The ODA grants commitments decrease current expenditure $\left(\pi_{25}\right)$, while the ODA loans and technical assistance commitments increase currents spending $\left(\pi_{24}\right.$ and $\pi_{26}$ ). The combined effect of aid commitments on current expenditure is positive. A $\$ 1$ increase in aid commitments increases current government spending by about $\$ 0.87$. This finding supports Franco-Rodriguez (2000) results and contradicts the results of Franco-Rodriguez et al (1998). The ODA loans commitments and technical assistance commitments reduce taxes $\left(\pi_{34}\right.$ and $\left.\pi_{36}\right)$, while ODA grants commitments increase taxes $\left(\pi_{35}\right)$. The combined effect of aid commitments on taxation is negative. An increase in aid commitments by $\$ 1$ reduces taxation by $\$ 0.30$. The ODA loans commitments increase public borrowing $\left(\pi_{74}\right)$ and the ODA grants commitments and technical assistance commitments reduce public borrowing $\left(\pi_{75}\right.$ and $\left.\pi_{76}\right)$. The combined effect of aid commitments on public borrowing is negative. An increase in aid commitments by $\$ 1$ decreases domestic borrowing by $\$ 1.11$.

\section{Summary and Conclusion}

This paper addresses the question of the relationship between aid and the public sector's policy variables in the context of East Africa. The paper uses endogenous and disaggregated aid variables. The main findings of the paper is that aid increases both public investment and recurrent government expenditure keeping in mind that the aid variables used are intended for development. On the other hand, aid seems to reduce the tax collection efforts. It is comforting to also observe that both the direct and indirect effects of aid on public borrowing are negative. This is in contrast to the findings of Franco-Rodriguez et al (1998) in the case of Pakistan. The estimates of the constraint equation parameters indicate that East African countries take ODA loans funds more seriously that ODA grants funds when spending on public investment. The proportion of ODA loans allocated to current government expenditure is much smaller that the proportion of ODA grants spent on current public expenditure. Thus, one may conclude that loans contribute more to the development efforts than grants. Therefore, donors should limit the amounts of grants extended to the least developed countries.

\section{References}

Ahmed, S. (2002). Impact of Aid on Fiscal Behavior: A Case Study of Pakistan (1980-2000). The Lahore Journal of Economics, 17, 117-24.

Franco-Rodriguez, S., M. McGillivray, M., \& O. Morrissey (1998). Aid and the Public Sector in Pakistan: Evidence with Endogenous Aid. World Development, 26, 1241-1250. http://dx.doi.org/10.1016/S0305-750X(98)00048-5

Franco-Rodriquez, S. (2000). Recent Advances in Fiscal Response Models with an Application to Costa Rica. Journal of International Development, $12(3), \quad 429-442$. http://dx.doi.org/10.1002/(SICI)1099-1328(200004)12:3<429::AID-JID660>3.0.CO;2-W

Gang, I. N., \& Khan, H. A. (1986). Foreign Aid and Public Expenditure in LDCs. Atlantic Economic Journal, 14, 56-8. http://dx.doi.org/10.1007/BF02304625

Heller, P. (1975). A Model of Public Fiscal Behavior in Developing Countries: Aid, Investment, and Taxation. American Economic Review, 65, 429-45.

Iqbal, Z. (1997). Foreign Aid and the Public Sector: A Model of Fiscal Behavior in Pakistan. The Pakistan Development Review, 36, 115-129. 
Khan, H.A., \& E. Hoshino. (1992). Impact of Foreign Aid on the Fiscal Behavior of LDC Governments. World Development, 20, 1481-1488. http://dx.doi.org/10.1016/0305-750X(92)90068-7

Mavrotas, G. (2004). Foreign Aid and Fiscal Response: Does Disaggregation Matter?. Weltwirtschaftliches Archiv, 138(3), 534-59. http://dx.doi.org/10.1007/BF02707953

Mavrotas, G. (2005). Aid heterogeneity: looking at aid effectiveness from a different angle. Journal of International Development, 17, 1019-36.

Mavrotas, G., \& B. Ouattara (2006). Aid Disaggregation and Public Sector in Aid-Recipient Countries: Some Evidence from Cote D'Ivoire. Review of Development Economics, 10(3), 434-51. http://dx.doi.org/10.1111/j.1467-9361.2006.00351.x

McGillivray, M., \& O. Morrissey. (2001). Fiscal Effects on Aid. WIDER Discussion, Paper No. 2001/61.

McGillivray, M., \& A. Ahmed. (1999). Aid, Adjustment and Public Sector Fiscal Behavior in the Philippines. Journal of the Asia-Pacific Economy, 4, 381-391. http://dx.doi.org/10.1080/13547869908724687

OECD. (2010). International Development Statistics, Paris: OECD.

Otim, S. (1996). Foreign Aid and Government Fiscal Behavior in Low-Income South Asian Countries. Applied Economics, 28, 927-3. http://dx.doi.org/10.1080/000368496328056

Phijaisant, E. (2010). Time Series of Endogenous Fiscal Response to Development Aid in Thailand. Research Journal of International Studies. 15, 12-26.

Please, S. (1967). Savings Through Taxation - Mirage or Reality?.Finance and Development, 4, 1-10.

White, H. (1994). Foreign Aid, Taxes and Public Investment: A Further Comment on Gang and Khan. Journal of Development Economics, 45, 155-63. http://dx.doi.org/10.1016/0304-3878(94)90065-5

World Bank. (2010). African Development Indicators. Washington, DC: World Bank.

Table 1. Estimates of the Structural Equations Parameters

\begin{tabular}{|c|c|c|c|c|c|}
\hline Parameter & Estimate (SE) & Parameter & Estimate (SE) & Parameter & Estimate (SE) \\
\hline$\rho_{1}$ & $0.47(0.1487)^{*}$ & $\beta_{1}$ & $0.0168(0.0178)$ & $\beta_{6}$ & $-0.0071(0.0265)^{*}$ \\
\hline$\rho_{2}$ & $0.93(0.0393)^{*}$ & $\beta_{2}$ & $0.0018(0.0606)^{*}$ & $\beta_{7}$ & $0.2679(0.0739)^{*}$ \\
\hline$\rho_{3}$ & $0.11(0.1223)$ & $\beta_{3}$ & $0.0023(0.0041)$ & $\beta_{8}$ & $0.0006(0.0061)$ \\
\hline$\rho_{4}$ & $0.23(0.0718)^{*}$ & $\beta_{4}$ & $1.1626(0.1203)^{*}$ & $\beta_{9}$ & $-1.2687(0.1450)^{*}$ \\
\hline$\rho_{5}$ & $0.73(00334)^{*}$ & $\beta_{5}$ & $0.6304(0.1418)^{*}$ & $\beta_{10}$ & $1.1464(0.1546)^{*}$ \\
\hline
\end{tabular}

Figures in parentheses next to each parameter's estimate are the corresponding standard errors. The $(*)$ indicates the estimate is significant at the $5 \%$ level or lower. 
Table 2. Direct Effect of Revenue Variables

\begin{tabular}{|l|c|}
\hline Description & Effect \\
\hline ODA Loans $\left(A_{1}\right)$ on Public Investment $\left(I_{q}\right)$ & 0.0939 \\
\hline ODA Loans $\left(A_{1}\right)$ on Current Spending $(G)$ & 03397 \\
\hline ODA Loans $\left(A_{1}\right)$ on Taxes $(T)$ & -0.5663 \\
\hline ODA Loans $\left(A_{1}\right)$ on Domestic Borrowing $(B)$ & -1.1692 \\
\hline ODA Grants $\left(A_{2}\right)$ on Public Investment $\left(I_{q}\right)$ & 0.0833 \\
\hline ODA Grants $\left(A_{2}\right)$ on Current Spending $(G)$ & 0.7297 \\
\hline ODA Grants $\left(A_{2}\right)$ on Taxes $(T)$ & 0.0173 \\
\hline ODA Grants $\left(A_{2}\right)$ on Domestic Borrowing $(B)$ & -1.6966 \\
\hline Technical Assistance $\left(A_{3}\right)$ on Public Investment $\left(I_{q}\right)$ & 0.1023 \\
\hline Technical Assistance $\left(A_{3}\right)$ on Current Spending $(G)$ & -0.0903 \\
\hline Technical Assistance $\left(A_{3}\right)$ on Taxes $(T)$ & -1.0230 \\
\hline Technical Assistance $\left(A_{3}\right)$ on Domestic Borrowing $(B)$ & -0.7565 \\
\hline Domestic Borrowing $(B)$ on Public Investment $\left(I_{q}\right)$ & 0.4977 \\
\hline Domestic Borrowing $(B)$ on Current Spending $(G)$ & 0.6521 \\
\hline Domestic Borrowing $(B)$ on Taxes $(T)$ & 0.2958 \\
\hline Domestic Borrowing $(B)$ on ODA Loans $\left(A_{1}\right)$ & -0.0116 \\
\hline Domestic Borrowing $(B)$ on ODA Grants & -0.1974 \\
\hline Domestic Borrowing $(B)$ on Technical Assistance & -0.0027 \\
\hline Taxes $(T)$ on ODA Loans $\left(A_{1}\right)$ & -0.0152 \\
\hline Taxes $(T)$ on ODA Grants $\left.A_{2}\right)$ & -0.0634 \\
\hline Taxes $(T)$ on Technical Assistance $\left(A_{3}\right)$ & -0.0024 \\
\hline Taxes $(T)$ on Domestic Borrowing $(B)$ & -0.8941 \\
\hline
\end{tabular}

These figures are calculated using Table 1 and the parameters specified in the structural equations (15)-(21).

Table 3. Estimates of the Parameters of the Reduced-Form Equations

\begin{tabular}{|c|c|c|c|c|c|}
\hline Parameter & Estimate & Parameter & Estimate & Parameter & Estimate \\
\hline$\pi_{11}$ & 1.0670 & $\pi_{12}$ & 0.0011 & $\pi_{13}$ & -0.2273 \\
\hline$\pi_{14}$ & -0.0360 & $\pi_{15}$ & 0.5246 & $\pi_{16}$ & 0.1376 \\
\hline$\pi_{21}$ & -1.2300 & $\pi_{22}$ & 0.9160 & $\pi_{23}$ & 0.8999 \\
\hline$\pi_{24}$ & 0.2006 & $\pi_{25}$ & -0.1973 & $\pi_{26}$ & 0.8690 \\
\hline$\pi_{31}$ & -0.0095 & $\pi_{32}$ & 0.0627 & $\pi_{33}$ & 1.1486 \\
\hline$\pi_{34}$ & -0.2681 & $\pi_{35}$ & 0.6344 & $\pi_{36}$ & -0.6686 \\
\hline$\pi_{41}$ & 0.0414 & $\pi_{42}$ & -0.0642 & $\pi_{43}$ & -0.0192 \\
\hline$\pi_{44}$ & 0.4028 & $\pi_{45}$ & 0.0855 & $\pi_{46}$ & 0.6192 \\
\hline$\pi_{51}$ & -0.1201 & $\pi_{52}$ & 0.0752 & $\pi_{53}$ & -0.0796 \\
\hline$\pi_{54}$ & -0.3972 & $\pi_{55}$ & 0.9397 & $\pi_{56}$ & 2.1114 \\
\hline$\pi_{61}$ & -0.0200 & $\pi_{62}$ & -0.0262 & $\pi_{63}$ & -0.0354 \\
\hline$\pi_{64}$ & -0.0190 & $\pi_{65}$ & -0.0166 & $\pi_{66}$ & 0.9234 \\
\hline$\pi_{71}$ & 2.0515 & $\pi_{72}$ & -0.4975 & $\pi_{73}$ & -0.1620 \\
\hline$\pi_{74}$ & 0.1181 & $\pi_{75}$ & -0.2487 & $\pi_{76}$ & -0.9783 \\
\hline
\end{tabular}




\section{Appendix}

These are the formulas of the parameters of the reduced-form equations (22)-(28).

$\pi_{11}=1-\gamma_{3} / \theta_{1}, \pi_{12}=-\left(\gamma_{3}-\gamma_{2}\right) / \theta_{1}, \pi_{13}=\left(\gamma_{3}-\rho_{4} \gamma_{2}\right) / \theta_{1}, \pi_{14}=\left(\gamma_{3}-\rho_{1} \gamma_{2}\right) / \theta_{1}, \pi_{15}=\left(\gamma_{3}-\rho_{2} \gamma_{2}\right) / \theta_{1}, \pi_{16}=\left(\gamma_{3}-\right.$ $\left.\rho_{3} \gamma_{2}\right) / \theta_{1}$

$\pi_{21}=\left(\gamma_{3}-\rho_{5} \gamma_{2}\right) / \theta_{2}, \pi_{22}=1-\left[\left(\gamma_{3}-\gamma_{2}\right)+\left(\gamma_{1}-\gamma_{2}\right)\right] / \theta_{2}, \pi_{23}=\left[\left(\gamma_{3}-\gamma_{2}\right)+\rho_{4}\left(\gamma_{1}-\gamma_{2}\right)\right] / \theta_{2}, \pi_{24}=\left[\left(\gamma_{3}-\gamma_{2}\right)+\rho_{1}\left(\gamma_{1}-\right.\right.$ $\left.\left.\gamma_{2}\right)\right] / \theta_{2}, \pi_{25}=\left[\left(\gamma_{3}-\gamma_{2}\right)+\rho_{2}\left(\gamma_{1}-\gamma_{2}\right)\right] / \theta_{2}, \pi_{26}=\left[\left(\gamma_{3}-\gamma_{2}\right)+\rho_{3}\left(\gamma_{1}-\gamma_{2}\right)\right] / \theta_{2}$

$\pi_{31}=\left(\gamma_{3}-\rho_{1} \gamma_{2}\right) / \theta_{3}, \pi_{32}=\left[\left(\gamma_{3}-\rho_{1} \gamma_{2}\right)+\left(\rho_{1} \gamma_{1}-\gamma_{2}\right)\right] / \theta_{3}, \pi_{33}=-\left[\left(\gamma_{3}-\rho_{1} \gamma_{2}\right)+\rho_{4}\left(\rho_{1} \gamma_{1}-\gamma_{2}\right)\right] / \theta_{3}, \pi_{34}=1-\left[\left(\gamma_{3}-\right.\right.$ $\left.\left.\rho_{1} \gamma_{2}\right)+\rho_{1}\left(\rho_{1} \gamma_{1}-\gamma_{2}\right)\right] / \theta_{3}, \pi_{35}=1-\left[\left(\gamma_{3}-\rho_{1} \gamma_{2}\right)+\rho_{2}\left(\rho_{2} \gamma_{1}-\gamma_{2}\right)\right] / \theta_{3}, \pi_{36}=1-\left[\left(\gamma_{3}-\rho_{1} \gamma_{2}\right)+\rho_{3}\left(\rho_{3} \gamma_{1}-\gamma_{2}\right)\right] / \theta_{3}$

$\pi_{41}=\left(\gamma_{3^{-}} \rho_{2} \gamma_{2}\right) / \theta_{4}, \pi_{42}=\left[\left(\gamma_{3^{-}} \rho_{2} \gamma_{2}\right)+\left(\rho_{1} \gamma_{1}-\gamma_{2}\right)\right] / \theta_{4}, \pi_{43}=-\left[\left(\gamma_{3^{-}} \rho_{2} \gamma_{2}\right)+\rho_{4}\left(\rho_{1} \gamma_{1}-\gamma_{2}\right)\right] / \theta_{4}, \pi_{44}=1-\left[\left(\gamma_{3}-\right.\right.$ $\left.\left.\rho_{2} \gamma_{2}\right)+\rho_{1}\left(\rho_{1} \gamma_{1}-\gamma_{2}\right)\right] / \theta_{4}, \pi_{45}=1-\left[\left(\gamma_{3}-\rho_{2} \gamma_{2}\right)+\rho_{2}\left(\rho_{2} \gamma_{1}-\gamma_{2}\right)\right] / \theta_{4}, \pi_{46}=1-\left[\left(\gamma_{3}-\rho_{2} \gamma_{2}\right)+\rho_{3}\left(\rho_{3} \gamma_{1}-\gamma_{2}\right)\right] / \theta_{4}$

$\pi_{51}=\left(\gamma_{3}-\rho_{3} \gamma_{2}\right) / \theta_{5}, \pi_{52}=\left[\left(\gamma_{3}-\rho_{3} \gamma_{2}\right)+\left(\rho_{1} \gamma_{1}-\gamma_{2}\right)\right] / \theta_{5}, \pi_{53}=-\left[\left(\gamma_{3}-\rho_{3} \gamma_{2}\right)+\rho_{4}\left(\rho_{1} \gamma_{1}-\gamma_{2}\right)\right] / \theta_{5}, \pi_{54}=1-\left[\left(\gamma_{3}-\right.\right.$ $\left.\left.\rho_{3} \gamma_{2}\right)+\rho_{1}\left(\rho_{1} \gamma_{1}-\gamma_{2}\right)\right] / \theta_{5}, \pi_{55}=1-\left[\left(\gamma_{3}-\rho_{3} \gamma_{2}\right)+\rho_{2}\left(\rho_{2} \gamma_{1}-\gamma_{2}\right)\right] / \theta_{5}, \pi_{56}=1-\left[\left(\gamma_{3}-\rho_{3} \gamma_{2}\right)+\rho_{3}\left(\rho_{3} \gamma_{1}-\gamma_{2}\right)\right] / \theta_{5}$ $\pi_{61}=\left(\gamma_{3}-\rho_{4} \gamma_{2}\right) / \theta_{6}, \pi_{62}=\left[\left(\gamma_{3}-\rho_{4} \gamma_{2}\right)+\left(\rho_{4} \gamma_{1}-\gamma_{2}\right)\right] / \theta_{6}, \pi_{63}=1-\left[\left(\gamma_{3}-\rho_{4} \gamma_{2}\right)+\rho_{4}\left(\rho_{4} \gamma_{1}-\gamma_{2}\right)\right] / \theta_{6}, \pi_{64}=-\left[\left(\gamma_{3}-\right.\right.$ $\left.\left.\rho_{4} \gamma_{2}\right)+\rho_{1}\left(\rho_{4} \gamma_{1}-\gamma_{2}\right)\right] / \theta_{6}, \pi_{65}=-\left[\left(\gamma_{3}-\rho_{4} \gamma_{2}\right)+\rho_{2}\left(\rho_{4} \gamma_{1}-\gamma_{2}\right)\right] / \theta_{6}, \pi_{66}=-\left[\left(\gamma_{3}-\rho_{4} \gamma_{2}\right)+\rho_{3}\left(\rho_{4} \gamma_{1}-\gamma_{2}\right)\right] / \theta_{6}$

$\pi_{71}=\left(\gamma_{3}-\rho_{5} \gamma_{2}\right) / \theta_{7}, \pi_{72}=\left[\left(\gamma_{3}-\rho_{5} \gamma_{2}\right)+\left(\rho_{3} \gamma_{1}-\gamma_{2}\right)\right] / \theta_{7}, \pi_{73}=-\left[\left(\gamma_{3}-\rho_{5} \gamma_{2}\right)+\rho_{4}\left(\rho_{5} \gamma_{1}-\gamma_{2}\right)\right] / \theta_{7}, \pi_{74}=-\left[\left(\gamma_{3}-\right.\right.$ $\left.\left.\rho_{5} \gamma_{2}\right)+\rho_{1}\left(\rho_{5} \gamma_{1}-\gamma_{2}\right)\right] / \theta_{7}, \pi_{75}=-\left[\left(\gamma_{3}-\rho_{5} \gamma_{2}\right)+\rho_{2}\left(\rho_{5} \gamma_{1}-\gamma_{2}\right)\right] / \theta_{7}, \pi_{76}=-\left[\left(\gamma_{3}-\rho_{5} \gamma_{2}\right)+\rho_{3}\left(\rho_{5} \gamma_{1}-\gamma_{2}\right)\right] / \theta_{7}$ where,

$\gamma_{1}=\sum_{i=1}^{7} \frac{1}{\alpha_{i}}, \gamma_{2}=\frac{1}{\alpha_{2}}+\sum_{i=1}^{5} \frac{\rho_{i}}{\alpha_{i+2}}, \quad \gamma_{2}=\frac{1}{\alpha_{2}}+\sum_{i=1}^{5} \frac{\rho_{i}^{2}}{\alpha_{i+2}}, \quad$ and $\theta_{i}=\left[\alpha_{i}\left(\gamma_{1} \gamma_{3}-\gamma_{2}^{2}\right)\right]$ for $\mathrm{i}=1,2,3,4,5,6,7$ 